\title{
A neurolinguística discursiva e a recuperação da capacidade comunicativa de sujeitos afásicos
}

\author{
The discursive neurolinguistic and recuperation of communicative ability in \\ aphasic subjects
}

\section{Vivian Meira de Oliveira}

Universidade do Estado da Bahia - UNEB-BA - Bahia - Brasil

\begin{abstract}
$\longrightarrow$
Resumo: Esta pesquisa apresenta uma análise de dados de linguagem patológica de adultos com lesão cerebral, portadores de afasia. Parte-se da hipótese de que a prática clínica delineada a partir do modelo teórico da Neurolinguistica Discursiva é fundamental tanto para a recuperação da capacidade comunicativa do sujeito afásico quanto para sua (re) inserção social, já que a afasia é uma patologia que afeta o uso da linguagem. Nesse processo de tratamento do distúrbio linguístico, o sujeito afásico faz uso de diferentes estratégias para recuperar sua capacidade comunicativa alterada e/ou perdida. No contexto pragmático, o diálogo é construído, ajudando o sujeito a constituir sentido(s) através da interlocução. Diante disso, adotamos a ideia de que há uma recuperação da capacidade comunicativa nos afásicos em detrimento de um processo de (re) aquisição de linguagem.
\end{abstract}

Palavras-chave: Afasia; Neurolinguística Discursiva; Recuperação da capacidade comunicativa.

\begin{abstract}
This study presents a pathological language data analysis of adult brain injury, aphasia patients. We started from the hypothesis that outlined clinical practice from the theoretical model of Neuro Discourse is crucial both for the recovery of communicative ability of aphasic as to their (re) integration, since Aphasia is a condition that affects the use of language. That the language disorder treatment process, the aphasic makes use of different strategies to recover amended and / or lost communication skills. In the pragmatic context, dialogue is built, helping the subject to make sense (s) through dialogue. Therefore, we have adopted the idea that there is a recovery of communicative skills in aphasic rather than a process of (re) language acquisition.
\end{abstract}

Keywords: Metaphor. Aphasia; Neurolinguistic Discursive; Recovery of communicative ability. 


\section{Introdução}

A hipótese geral que guia essa pesquisa é a de que a intervenção clinica sob 0 modelo da Neurolinguística Discursiva (ND) pode auxiliar na recuperação da capacidade comunicativa de afásicos, como também na (re)inserção social dos mesmos. Assumimos com isso que a ND atua nas soluções pragmáticas (cf. COUDRY, 1996, 2002) e, devido a isso, busca contribuir para um direcionamento da prática clínica.

Diferente de algumas pesquisas na literatura que levantaram a hipótese de que no quadro do agramatismo pode ocorrer reaquisição de linguagem (cf. GREGOLIN-GUINDASTE, 1996), discutiremos que o que se recupera no processo de intervenção clinica é a capacidade comunicativa do afásico.

As questões que nos motivaram a desenvolver esse artigo foram: (i) como pode ser interpretada a recuperação linguística do afásico e qual o papel da intervenção clínica dimensionada a partir da ND sob essa recuperação? (ii) Qual a diferença em termos teóricos e pragmáticos entre (re)aquisição de linguagem e recuperação da capacidade comunicativa de sujeitos com afasia?

Quando dizemos que a ND pode ajudar na recuperação linguística de afásicos, não queremos afirmar que um modelo teórico de língua é capaz de fazê-lo. Evidentemente, o que observamos são intervenções clínicas podendo ser dimensionadas a partir de pressupostos teóricos de modelos, como o que é feito a partir da ND, mas modelos em si não recuperam patologias. Defendemos nesse artigo que o que é possível é a recuperação da capacidade de comunicação do sujeito afásico por meio de intervenções clinicas dimensionadas a partir de pressupostos teóricos da ND.

Os déficits de linguagem podem ser explicados de diversas formas, a depender da perspectiva de língua adotada pelo pesquisador. As afasias podem, por exemplo, fazer referência exclusivamente à fala, ser uma expressão dela e não do conhecimento linguístico apropriadamente (cf. TUMIATE, 2007), e para outros (cf. GRODZINSKY, 1990; NOVAES,
2006), os déficits de linguagem podem se relacionar à habilidade cognitiva, já que linguagem é uma dessas habilidades para alguns pesquisadores. De todo modo, ainda se faz necessário muitos estudos para sabermos até que ponto poderia dizer que uma determinada afasia se relaciona com a competência de um falante, ao conhecimento que este tem da língua e aos aspectos cognitivos da linguagem ou apenas ao uso da língua, à fala. Nessa pesquisa, adotamos a perspectiva de que a afasia está relacionada ao uso da linguagem, ou seja, à fala.

O fato, por exemplo, do falante com agramatismo produzir sentenças desprovidas de uma estrutura sintática coerente pode não apresentar, empiricamente, nenhuma relação com a capacidade/competência sintática gerativa desse falante, pois a questão da agramaticalidade na fala serve para ilustrar a produção de sentenças e não significa necessariamente que faça referência a problemas no procedimento gerativo de sentenças, ao processo cognitivo em si. Diante disso, entendemos linguagem como uma faculdade humana, um dispositivo inato de conhecimento. A mente, nesse caso, organiza-se em módulos cognitivos, sendo a linguagem um desses módulos (cf. CHOMSKY, 1981). E, quando falamos em alterações/patologias de linguagem em sujeitos afásicos, esse sistema cognitivo da linguagem na mentelcérebro não é abalado, o conhecimento linguistico permanece intacto; no entanto, seu uso, sua habilidade de falar pode sofrer déficitlalteração a depender da lesão ocorrida. As afasias, nesse caso, relacionam-se ao uso do conhecimento linguístico, ao uso da língua.

$\mathrm{O}$ artigo estrutura-se da seguinte forma: $\mathrm{Na}$ primeira seção, apresentaremos o conceito de afasia e de língua para a ND e a importância desta no direcionamento da prática clínica. Na segunda seção, serão apresentados alguns dados de sujeitos afásicos, a fim de mostrar a importância da ND para a intervenção clínica nos casos de patologias de linguagem. Na terceira seção, abordaremos o processo de aquisição de linguagem em crianças sem patologia com o processo de (re)aquisição de 
linguagem em sujeitos com patologia linguística e defenderemos a favor de uma recuperação da capacidade comunicativa alterada pela lesão em detrimento de uma (re)aquisição e, na última seção, serão apresentadas as nossas considerações finais.

\section{A neurolinguística discursiva: implicações teóricas na intervenção clínica}

As alterações no uso da linguagem causadas por uma lesão cerebral sao chamadas de afasia. $A$ significa não e fasia, falar. Nesse caso, a pessoa não consegue falar o que ela gostaria e a afasia pode ser entendida como um distúrbio na formulação elou compreensão da linguagem. De certo modo, afásicos podem entenderlcompreender a linguagem, mas sentem dificuldade para construir sentenças ou achar as palavras certas; outros falam em demasia, mas usam construções difíceis de se compreender.

Pessoas que sofrem de afasia em geral têm a sua competência intelectual intacta. A severidade dessa patologia dependerá da localização e da extensão da lesão cerebral e da competência linguística anterior do falante. Para o processo de recuperação e intervenção clínica de dados patológicos de afásicos, defendemos, como Coudry (1988, 1996, 2002), que a linguagem deve ser vista como uma atividade significativa, uma prática discursiva, uma vez que o uso efetivo da língua em práticas sociais, no decorrer do acompanhamento dos sujeitos afásicos, fará com que estes se interajam com a própria língua, com si mesmos, com o mundo, expondo suas dificuldades, não só as linguísticas, como também as sociais. A língua será um meio de expor o déficit do sujeito, a partir de sua interação no contexto pragmático e sua recuperação se dará também através desse mesmo "canal", o canal linguístico.

Seria então a prática clínica essa busca do dado-achado (cf. COUDRY, 1996), que pode ser entendido como o "produto da articulação de teorias sobre o objeto que se investiga com a prática de avaliação e acompanhamento clínico de processos lingüístico-cognitivos" (COUDRY, 1996, p. 183).
Acreditamos que esse tipo de intervenção pode fornecer informações que visam a complementar a prática discursiva com a linguagem, direcionada pela ND; a intervenção sugerida pela ND, como vem sendo desenvolvida por Coudry (1988, 2002), faz com que as dificuldades linguísticocognitivas sejam reconstruídas através de soluções outras que o sujeito vai encontrando no uso de recursos e estratégias que Ihe são oferecidas como caminho para a comunicação. De fato, essa intervenção clínica vai mostrando aos sujeitos as várias formas de sua (re)inserção no meio social. Nisso se baseia o trabalho de Maria Irma Hadler Coudry no Centro de Convivência de Afásicos (CCA), na UNICAMP, desde 1982. Essas situações discursivas propostas tem como foco não apenas o nível onde há déficit linguístico, como também uma articulação entre os outros níveis da língua, o que ficou alterado devido à lesão e o que foi inalterado.

A concepção de linguagem utilizada pela Neurolinguística Discursiva nos estudos em Patologia é aquela que é historicamente construída, é um trabalho pelo qual, histórica e culturalmente, o homem organiza e dá forma a suas experiências (cf. FRANCHI, 1977). Concepção sócio-histórica tomada como lugar de interação humana, de interlocução e sem isso não se pode falar propriamente de linguagem. Esta é determinada apenas nas relações que se estabelecem, pois o sujeito se relaciona com outros pela linguagem. Tomando esse pressuposto como base, a ND é constituída por um conjunto de teorias e práticas, cuja concepção de linguagem, ao contrário de uma visão organicista, concebe língua, discurso, cérebro e mente como construtos humanos que se relacionam (cf. COUDRY, 2008). E o tratamento ocorre através de sessões coletivas e individuais, mediante, sobretudo, o uso social da fala, escrita, leitura; as atividades se baseiam em diálogos sobre a agenda de cada um, o noticiário falado e escrito, o uso social do corpo, na culinária conjunta, jogos interativos, dentre outras atividades.

A afasia é uma patologia que afeta o uso da linguagem e para entendê-la é necessário conhecer o funcionamento da língua. Luria (1981) propõe que o 
cérebro trabalhe de maneira integrada e só uma visão baseada no que chamamos hoje de plasticidade cerebral, que permite que outras áreas se rearranjem para assumir funções modificadas por uma lesão, sustenta a possibilidade de suprir os déficits de linguagem que essa mesma lesão estabelece.

\section{Fig. 1: Áreas integradas do cérebro}

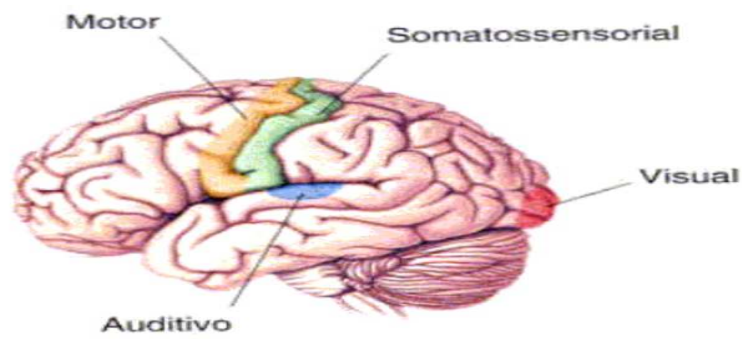

Como mostra a Figura 1, o cérebro é composto por diferentes partes; sabemos que a linguagem constitui uma atividade complexa, tentar falar não basta acionar a parte motora do cérebro e não é porque ocorre uma lesão em uma área que outras áreas cerebrais não possam ser ativadas. Entender que há plasticidade cerebral significa assumir que patologias de linguagem podem sofrer intervenção e quando o afásico não consegue dizer alguma palavra, ele pode usar outros processos de (re)significação a partir de gestos, desenhos, escrita, de palavras sinônimas etc para dialogar com o outro.

É fundamental que haja interlocução entre paciente e investigador, pois nesse diálogo "há exposição em câmara lenta do processamento patológico quando a linguagem se apresenta em funcionamento. Aí se vêem o nível lingüístico alterado e a repercussão dessa alteração nos demais níveis" (COUDRY, 1996, p. 187).

Nesse processo de tratamento do distúrbio linguístico, o sujeito afásico, diante da impossibilidade que a afasia coloca, faz uso de diferentes estratégias para recuperar sua capacidade comunicativa alterada, ele encontra outros meios para (re)significar - lexicais, gramaticais, corporais, gestuais etc. E é nesse sentido que o conceito de linguagem assumido pela ND toma sentido, pois o discurso, o diálogo é construído, mesmo que haja um nível lesionado, o contexto pragmático ajuda o sujeito a constituir sentido(s) através da interlocução. Veja um exemplo, na sessão do dia 19-10-2005, em que RS, um sujeito afásico, tenta escrever um bilhete para a investigadora, parabenizando-a pelo seu aniversário. Ele quer escrever a palavra "parabéns", mas afirma que sabe como é a escrita, mas não consegue selecionar a ordenação das letras. Então, para auxiliá-lo, a investigadora começa a soletrar as letras, o que o leva a escrever mais rápido a palavra e concluir o bilhete, como mostra o texto a seguir

Fig. 2: Bilhete de aniversário

$$
\begin{aligned}
& \text { MAZA } \\
& \text { FELIFIDADESI PARABFNS } \\
& \text { Ratrige }
\end{aligned}
$$

Fonte: Gomes (2008, p. 111).

Tomar a linguagem como atividade significativa pode contribuir para o tratamento de processos de significação alterados pela patologia. $\mathrm{Na}$ próxima seção, apresentaremos alguns dados de atividades linguísticas de afásicos, de modo a comprovar a importância da aplicação de estratégias sugeridas pelo modelo da ND no tratamento de patologias de linguagem.

3 Dados linguísticos de afásicos: a importância da nd para a recuperação da capacidade comunicativa de pessoas com lesão cerebral

São várias as estratégias utilizadas na intervenção clínica sob o modelo da ND. Com o 
intuito de demonstrar a importância desse modelo na recuperação social de afásicos, apresentaremos dados linguísticos patológicos e a forma como esses foram reconduzidos a partir do modelo de intervenção proposto pela ND.

RS, 21 anos, estudante, foi vítima de um traumatismo craneo-encefálico, responsável por alguns estados de afasia (cf. COUDRY, FREIRE, GOMES, 2006; GOMES, 2008). Com a ajuda da investigadora, representando estar em uma situação real, RS consegue escrever uma lista de compras. A investigadora "pede a ele que diga o nome da fruta de que mais gosta e ele diz, prontamente: 'morango'. Quando RS, descrente, começa a escrever essa palavra, espanta-se consigo mesmo, pois consegue escrevê-la inteira, bem mais rápido do que faria meses antes" (GOMES, 2008, p. 139). Observe a figura a seguir:

Fig. 3: Lista de frutas

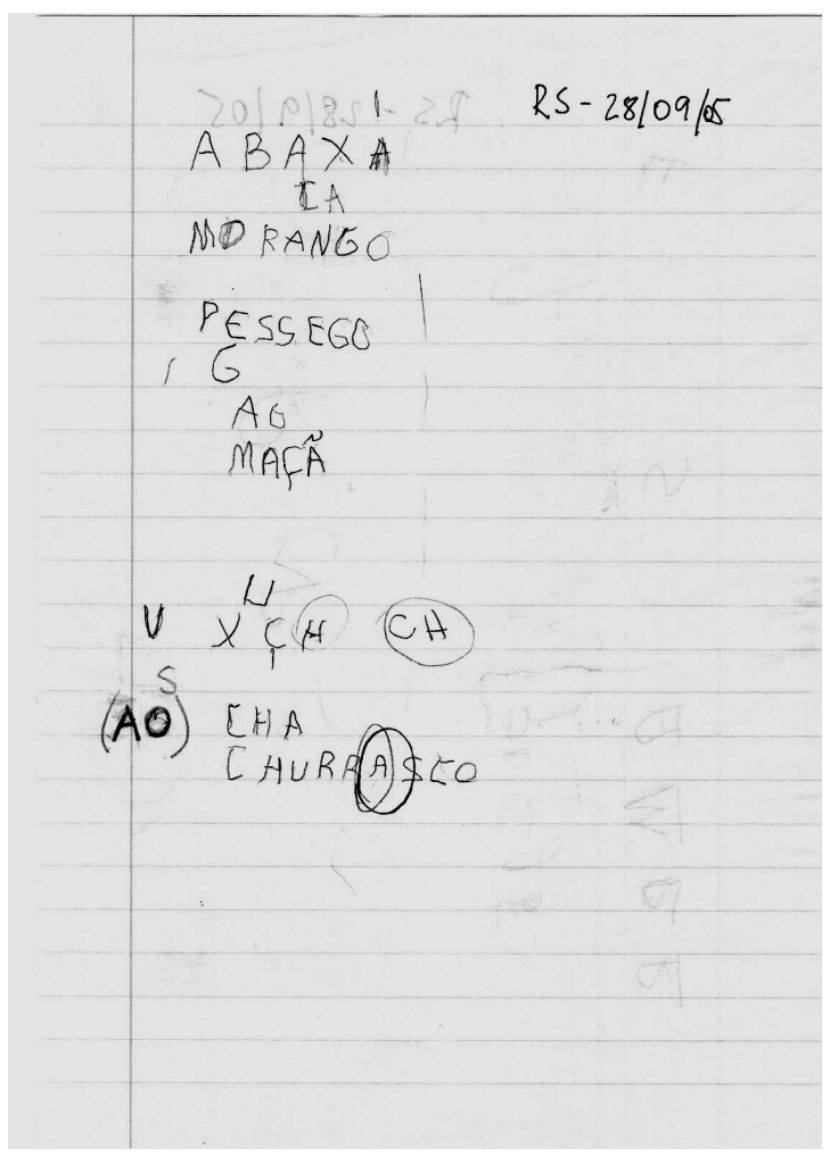

Fonte: Gomes (2008, p. 111).

Outro dado que será apresentado será o de P. P, 60 anos, funcionário público, sofreu, em 1981, um aneurisma e foi submetido a uma cirurgia e, em
1982, sofreu um Acidente Vascular Cerebral (AVC). Exames de tomografia indicaram lesão nas áreas têmporo-parieto-occipital esquerda (cf. COUDRY, 1988). P. foi encaminhado ao Centro de Convivência de Afásicos, em 1983, e foi acompanhado semanalmente por Coudry, sendo diagnosticado com agramatismo, que é uma patologia com déficit sintático.

O sujeito com agramatismo compreende as sentenças ${ }^{1}$, mas sente dificuldades em organizá-las sintaticamente, estruturalmente, o que levou a literatura na área a designar que esses sujeitos tenham seu nível sintático totalmente alterado pela lesão, de forma que não Ihe é possível manter a integridade da produção sintática. As definições de agramatismo não são uniformes, mas todas elas referem-se às falas afásicas, pouco inteligíveis, e não ao conhecimento linguístico do afásico. Grodzinsky (1990), pautado nos postulados chomskianos, busca caracterizar formalmente o agramatismo e afirma que valores como Tempo e Concordância em INFL estão apagados nesse tipo de afasia, na verdade, são omitidos ou substituídos, assim como preposições, determinantes e complementos. $O$ autor afirma ainda que preposições regidas, núcleo de PP em verbos intransitivos, são omitidas.

P. passa por esses momentos de instabilidades com sua língua, pois parece saber o que dizer, às vezes não sai o que vai dizer e às vezes produz sentenças totalmente desordenadas. Isso caracteriza parte da afasia desse sujeito.

A partir de uma análise longitudinal, tentaremos mostrar uma evolução do quadro patológico de P., apresentando alguns de seus dados, inclusive aqueles do início do atendimento terapêutico. Na sessão de 13/09/1984, a investigadora tenta simular a produção de uma carta

\footnotetext{
Alguns pesquisadores detectaram em pacientes com agramatismo algum déficit de compreensão em algumas produções sintáticas, levantando a hipótese da existência de um déficit gramatical central nos pacientes estudados (cf. Zurif, Caramazza e Myerson, 1972 apud Nespoulouc e Dordain, 1993).
} 
por $\mathrm{P}$, de modo a levá-lo a explicar os procedimentos necessários para o envio da mesma.

\begin{tabular}{|l|l|l|}
\hline $\begin{array}{l}\text { No } \\
\text { a do } \\
\text { Locu } \\
\text { tor }\end{array}$ & Transcrição \\
\hline 1 & INV & $\begin{array}{l}\text { Conta para mim o que o senhor precisa } \\
\text { fazer para mandar uma carta para } \\
\text { alguém. }\end{array}$ \\
\hline 2 & P & Marília ... Marilia. \\
\hline 3 & INV & $\begin{array}{l}\text { O senhor vai mandar uma carta para } \\
\text { Marilia? É uma amiga do senhor? } \\
\text { cidade ou pessoa? Ela mora em Marília } \\
\text { ou se chama Marília? }\end{array}$ \\
\hline 4 & P & Sônia. \\
\hline 5 & INV & Acabou de escrever, faz o quê? \\
\hline 6 & P & Envelope. \\
\hline 7 & INV & O que faz com o envelope? \\
\hline 8 & P & Correio. \\
\hline 9 & INV & O que faz aqui? \\
\hline 10 & P & Selo. \\
\hline 11 & INV & É de graça? \\
\hline 13 & P & Dinheiro. \\
\hline
\end{tabular}

Quadro 1 : Sessão de 13/09/1984

Fonte: (GREGOLIN-GUINDASTE, 1996, p. 113)

Observe que nessa sessão, P. se limita a usar apenas itens lexicais nominais, de modo a responder de imediato à questão da investigadora. $\mathrm{Na}$ sessão do dia 21/03/1986, a investigadora pede a $P$ para descrever o que aconteceu com três fotos e desenvolve um diálogo a partir disso, como mostra os dados a seguir:

\begin{tabular}{|l|l|l|}
\hline No. & $\begin{array}{l}\text { Sigla } \\
\text { do } \\
\text { Locut } \\
\text { or }\end{array}$ & Transcrição \\
\hline 1 & INV & O que que caiu? \\
\hline 2 & P & Fotos. \\
\hline 3 & INV & Então fala... As três fotos caíram \\
\hline 4 & P & Três fotos. \\
\hline 5 & INV & Caíram. \\
\hline 6 & P & Caindos, cairos, caindo, cair. \\
\hline
\end{tabular}

Quadro 2: Sessão do dia 21/03/1986

Fonte: (GREGOLIN-GUINDASTE, 1996, p. 119).

Apresentar uma afasia sintática não significa que haja um comprometimento da compreensão e a participação do sujeito no discurso, como foi o caso de $P$, no mais das vezes, mostra isso. Nas seções de 1986, P consegue ordenar mais a estrutura da sentenca, apesar de ainda apresentar dificuldade na produção de flexão verbal, o que pode ser observado também em uma sessão 07/02/1986, descrita a seguir.

\begin{tabular}{|l|l|l|}
\hline No. & $\begin{array}{l}\text { Sigla } \\
\text { do } \\
\text { Locu } \\
\text { tor }\end{array}$ & Transcrição \\
\hline 1 & INV & O que o Montoro veio fazer aqui? \\
\hline 2 & P & $\begin{array}{l}\text { Foi lá no presídio. Depois bandeira, como } \\
\text { chama? }\end{array}$ \\
\hline 3 & INV & O que ele foi fazer na UNICAMP? \\
\hline 4 & P & Foi lá na ... Como chama é... \\
\hline 5 & INV & Foi inau... \\
\hline 6 & P & Inauguras. \\
\hline 7 & INV & Ele foi inaugurar. Ele já ... \\
\hline 8 & P & Inaugurando, inaugurandos. \\
\hline 9 & INV & Inaugurou. \\
\hline 10 & P & Ah! Meu Deus; ina ... inaugurou... \\
\hline 11 & INV & Montoro veio a Campinas? \\
\hline 12 & P & Montoro foi. \\
\hline & & \\
\hline
\end{tabular}

Quadro 3: Sessão de 07/02/1986

Fonte: (GREGOLIN-GUINDASTE, 1996, p. 120) 
Se comparado esse dado com os de 1994, observamos que há uma melhora do quadro, porque, mesmo $\mathrm{P}$ não produzindo todas as sentenças, há interação no discurso, tentativa de comunicação, o que demonstra recuperação da capacidade comunicativa. Veja a seguir dados ocorridos na sessão de 15/07/1994:

\begin{tabular}{|l|l|l|}
\hline No. & $\begin{array}{l}\text { Sigla } \\
\text { do } \\
\text { Locu } \\
\text { tor }\end{array}$ & Transcrição \\
\hline 1 & INV & $\begin{array}{l}\text { Por que o senhor não veio na segunda } \\
\text { passada, que teve grupo? }\end{array}$ \\
\hline 2 & P & $\begin{array}{l}\text { Eu tava no ponto, aquela senhora } \\
\text { japonesa estava lá esperando. Era ... } \\
\text { vim aqui, estava fechado. }\end{array}$ \\
\hline
\end{tabular}

Quadro 4: Sessão de 15/07/1994

Fonte: (GREGOLIN-GUINDASTE, 1996, p. 131)

Na sessão de 15/07/1994, pode ser observado como a capacidade comunicativa de $\mathrm{P}$ foi recuperada se comparada com os dados de 1984. Recuperação aqui no sentido de maior participação do sujeito no discurso, seja pela fala, por gestos, pela escrita, pintura. $\mathrm{P}$ nos dados de 1994 consegue produzir mais sentenças, alcançando evolução em seu quadro patológico, sendo registrado melhor desempenho nas atividades comunicativas. Levando em conta a gravidade da afasia, seu quadro evidentemente evoluiu para menos grave, pois houve uma recuperação da capacidade comunicativa a partir do uso de diferentes recursos.

Outro dado observado na produção de $\mathrm{P}$ diz respeito às estruturas passivas. Pacientes com agramatismo sentem dificuldades em produzir estruturas passivas, mas de forma geral compreendem e produzem as sentenças transitivas simples, como as ativas (cf. GREGOLINGUINDASTE, 1996). No entanto, não há consenso na literatura a respeito do nível de compreensão desses sujeitos com relação à sentença passiva.

Para Grodzinsky (1990), o agramático parece inverter as funções de agente/tema nas passivas, não consegue interpretá-las, ao passo que com as ativas seu desempenho é muito bom. Gregolin-Guindaste (1996, p. 196) afirma que em P. "à compreensão desta estrutura está preservada, apesar de permanecerem problemas na representação em FF." P compreende sentença passiva, mas sente dificuldades na produção ou repetição dessas sentenças.

Nespoulouc e Dordain (1993), a partir de dados linguísticos de um sujeito, diagnosticado com agramatismo, afirmaram que o paciente apresentava dificuldades na produção de diferentes sentenças, independente de sua complexidade sintática, mas que, em momento algum, foi observada dificuldade para a compreensão:

[...] M Clermont omite ou substitui um grande número de palavras gramaticais mas a taxa de erros não parece ser função da complexidade sintática das frases. $\mathrm{Na}$ verdade, tem-se a nítida impressão de que cada vez que M. Clermont deve produzir uma palavra gramatical ele sente dificuldade, a qual independe da complexidade intrínseca da frase. (NESPOULOUC E DORDAIN, 1993, p. 19)

M. Clermont apresentou as mesmas dificuldades que $P$. em gerar estruturas sintáticas, mesma as compreendendo ${ }^{2}$. Em algumas sessões, $P$ só consegue repetir as construções passivas sem o agente, como em A laranja é apanhada, A mata foi queimada (cf. GREGOLIN-GUINDASTE, 1996, p. 203). Em outros casos, o sujeito constrói outras sentenças substituindo o by-phrase por outras preposições, como aconteceu na sessão de 21/05/1991. Nessa sessão, a atividade foi montagem de sentenças com cartões recortados e, mesmo com a leitura da investigadora, o paciente sente dificuldades na produção das construções passivas. Depois de algumas atividades, ele consegue produzir algumas passivas. Por exemplo, na sentença $A$ fita foi dada por Oriel, (Gregolin-Guindaste, 1996, p. 199) ele consegue produzir (lendo): A fita foi dada a Oriel e

\footnotetext{
2 Como afirmam Bear, Connors e Paradiso (2002, p. 649): "Um dos fatos tristes, porém fascinantes acerca da afasia, é a diversidade das síndromes que ocorrem após um acidente vascular cerebral. Enquanto as síndromes desafiam qualquer modelo de linguagem, cada uma delas oferece uma pista para nossa compreensão do processamento da linguagem."
} 
depois de outras tentativas com a ajuda da investigadora produz a passiva. Em outras sentenças, $\mathrm{P}$ usa as preposições a e para no lugar do by-phrase

Mesmo demonstrando um quadro de melhoria, P. ainda apresenta dificuldade com a produção de passivas, o que demonstra que recuperar a capacidade comunicativa não se restringe a um ato de fala. Na sessão de 15/07/1994, em uma atividade de montagem de cartões, observe que $P$ não apresenta dificuldade em repetir estrutura ativa (como na linha 3). No entanto, sente dificuldade na repetição das passivas, mas a compreende, como nas linhas $35 / 37$ e, nas linhas $33 / 44$, ele consegue repetir a sentença trabalhada.

\begin{tabular}{|c|c|c|}
\hline No & $\begin{array}{l}\text { Sig } \\
\text { la } \\
\text { do } \\
\text { Lo } \\
\text { cut } \\
\text { or }\end{array}$ & Transcrição \\
\hline 1 & $\mathrm{P}$ & Tesoura pra que? \\
\hline 2 & $\begin{array}{l}\text { IN } \\
\text { V }\end{array}$ & $\begin{array}{l}\text { Tesoura é para cortar os cartões. } \\
\text { Repete: O menino comeu o bolo }\end{array}$ \\
\hline 3 & $P$ & O menino comeu o bolo \\
\hline 4 & $\begin{array}{l}\text { IN } \\
\text { V }\end{array}$ & O bolo foi comido pelo menino \\
\hline 5 & $\mathrm{P}$ & Menino... \\
\hline 6 & $\begin{array}{l}\text { IN } \\
\text { V }\end{array}$ & $\begin{array}{l}\text { Escuta primeiro: } \mathrm{O} \text { bolo foi comido pelo } \\
\text { menino. }\end{array}$ \\
\hline 7 & $\mathrm{P}$ & O bolo comeu...não...o bolo... (...) \\
\hline 30 & $\begin{array}{l}\text { IN } \\
\text { V }\end{array}$ & O bolo foi comido pelo menino. \\
\hline 31 & $\mathrm{P}$ & O bolo comeu... O bolo menino... \\
\hline 32 & $\begin{array}{l}\text { IN } \\
\text { V }\end{array}$ & $\begin{array}{l}\text { O bolo foi comido pelo menino. Agora } \\
\text { leia esta frase. }\end{array}$ \\
\hline 33 & $\mathrm{P}$ & $\begin{array}{l}\text { O bolo comido pe... } \\
\text { O bolo foi comido pelo menino. }\end{array}$ \\
\hline 34 & $\begin{array}{l}\text { IN } \\
\text { V }\end{array}$ & $\begin{array}{l}\text { Isso o senhor leu. Agora responde: Quem } \\
\text { comeu o bolo? }\end{array}$ \\
\hline 35 & $\mathrm{P}$ & Menino. \\
\hline 36 & $\begin{array}{l}\text { IN } \\
\text { V }\end{array}$ & O que o menino fez? \\
\hline
\end{tabular}

\begin{tabular}{|l|l|l|}
\hline 37 & P & Comeu o bolo. \\
\hline 38 & $\begin{array}{l}\text { IN } \\
\text { V }\end{array}$ & $\begin{array}{l}\text { Repete de novo: O bolo foi comido pelo } \\
\text { menino. }\end{array}$ \\
\hline 39 & P & $\begin{array}{l}\text { O bolo foi comido...o bolo foi comido do } \\
\text { menino...menino... menina... menina. }\end{array}$ \\
\hline 40 & $\begin{array}{l}\text { IN } \\
\text { V }\end{array}$ & Pelo menino. \\
\hline 41 & P & O bolo foi comido de... de... \\
\hline 42 & $\begin{array}{l}\text { IN } \\
\text { V }\end{array}$ & Pelo menino, menino... menino. \\
\hline 43 & P & De... pelo \\
\hline 44 & P & O bolo foi comido pelo menino. \\
\hline
\end{tabular}

Fonte: (GREGOLIN-GUINDASTE, 1996, p. 203-204)

Primeiro, $\mathrm{P}$ produz $\mathrm{O}$ bolo...menino comeu. Depois faz outra ativa: $O$ bolo comeu. Em seguida, $O$ bolo foi comido, depois usa a preposição para e de: comido para menino; o bolo foi comido do menino e, em outra tentativa, $\mathrm{P}$ consegue produzir a passiva: $\mathrm{O}$ bolo foi comido pelo menino. Os dados a seguir ocorrem numa sessão desse mesmo dia:

\begin{tabular}{|c|c|c|}
\hline No & $\begin{array}{l}\text { Sigla } \\
\text { do } \\
\text { Locu } \\
\text { tor }\end{array}$ & Transcrição \\
\hline 1 & INV & $\begin{array}{l}\text { Aqui está escrito pela criança. Agora o senhor } \\
\text { não lê. Olha pra mim e repete: } 0 \text { brinquedo } \\
\text { foi quebrado pela criança. }\end{array}$ \\
\hline 2 & $\mathrm{P}$ & O brinquedo foi quebrado de criança. \\
\hline 3 & INV & É “pela criança”. \\
\hline 4 & $\mathrm{P}$ & De... dela. \\
\hline 5 & INV & Pela criança. \\
\hline 6 & $\mathrm{P}$ & $\begin{array}{l}\text { Criança. } \\
\text { Os brinquedos foi quebrou, está certo? }\end{array}$ \\
\hline 7 & INV & Quebrado. \\
\hline 8 & $\mathrm{P}$ & Quebrado... \\
\hline 9 & INV & Pela criança... \\
\hline 10 & $\mathrm{P}$ & Pela criança. \\
\hline 11 & INV & $\begin{array}{l}\text { De novo: } 0 \text { brinquedo foi quebrado pela } \\
\text { criança. }\end{array}$ \\
\hline 12 & $\mathrm{P}$ & O brinquedo foi quebrado de da... \\
\hline 13 & INV & Pela ... \\
\hline
\end{tabular}

Quadro 6: Sessão do dia 15/07/1994

Fonte: (GREGOLIN-GUINDASTE, 1996, p. 204-205) 
Conhecendo o funcionamento da linguagem, fica mais cômodo na intervenção clinica serem criadas situações em que auxilie $\mathrm{P}$ ou outro afásico a fazerem uso de sentenças passivas, de modo a direcioná-los na produção desses tipos de sentenças ou no uso de outras estratégias linguísticas para ajudar a superar esse déficit. Ao analisar o dadoachado, na intervenção, podem-se criar situações mais diretas para ajudar na recuperação do paciente, inserindo no ambiente dados essenciais para a recuperação de sua capacidade comunicativa. $P$, nesse caso, faz uso de outros recursos, como preposições diversas, para tentar ligar o agente da passiva à locução verbal. E como afirma Coudry (1996, p. 187):

Os problemas de $\mathrm{P}$ são sintáticos, mas demandam soluções pragmáticas. Se $\mathrm{P}$ fosse avaliado pelo teste, revelar-se-ia 0 agramatismo, mas sem esgotar a sua caracterização: já a avaliação dos processos sintáticos, no interior do funcionamento da linguagem, é capaz de não só caracterizar o agramatismo, como também de relacioná-lo a outros níveis lingüísticos e de explicar os recursos expressivos de que $\mathrm{P}$ lança mão.

A prática clínica da ND, pautando-se em diferentes teorias da língua, promove uma articulação entre os níveis linguísticos, buscando explicar dados patológicos e encontrando soluções pragmáticas para esses quadros.

Comparando os dados de $\mathrm{P}^{3}$ de 1984, de 1986 e os de 1994, verificamos que, em 1984, P fazia grande uso de núcleos nominais nas situações discursivas, ao passo que dez anos depois esse quadro discursivo muda, ele consegue se interagir mais no discurso, com produção de sentenças, ou seja, mesmo ainda apresentando um estado de afasia, há uma melhora no seu quadro patológico, pois parte de sua capacidade comunicativa foi recuperada.

Outro dado pode ser observado nas atividades desenvolvidas no Centro de Convivência de Afásicos que envolvem CR. CR sofreu um Acidente Vascular Cerebral, tem 51 anos e tem um quadro afásico

\footnotetext{
${ }^{3}$ Para detalhes de uma análise longitudinal dos dados de $\mathrm{P}$, ver Guindaste (1996).
}

correspondente a afasia motora aferente e também eferente (cf. COUDRY, 2008). Coudry (2008) relata que em uma sessão grupal, em agosto de 2002, em que o tema foi a má condução da seleção brasileira pelo técnico Parreira, CR, com um gesto de mão pediu que o grupo, no meio da discussão, esperasse um pouco, o que foi atendido. Abaixou a cabeça e ficou pensativo. Uma das investigadoras the ofereceu um papel e CR imediatamente fez o desenho na prancheta de algo que parecia ser enrolado. Nesse momento, a investigadora perguntou se ele quis dizer que o Parreira apenas enrolou e ele, muito contente, disse "opa", expressão comumente usada por ele para expressar concordância e contente por ter emitido a sua opinião na discussão calorosa. Coudry (2008) conclui que o desenho, nesse caso, foi o meio significativo, o processo alternativo por meio do qual CR expressou, disse o que se pretendia.

Isso resume o objetivo da ND: ajudar na recuperação da capacidade comunicativa do sujeito e da sua (re)inserção social, de modo que o mesmo volte a exercer diferentes papéis. Esses dados demonstram como a intervenção clínica delineada a partir da Neurolinguística Discursiva, como desenvolvida por Coudry (1988, 1996, 2002), tem contribuído para a recuperação de afásicos. $\mathrm{Na}$ verdade, a inserção dos sujeitos em atividades significativas pode ajudar na reorganização cerebral desses sujeitos, pois o cérebro, por ser dinâmico, tende a se adaptar às diversas situações que lhe são impostas. E essa adaptação pode ser explicada pela Plasticidade Cerebral, capacidade que é dotado o cérebro humano para se recuperar de quadros de lesão. O cérebro tende a funcionar, mesmo lesionado, de forma integrada e sistemática, definindo seu funcionamento tanto a partir de aspectos cognitivos, internos, quanto de fatores discursivos, externos.

Gostaríamos de dizer ainda que, quando o assunto é linguagem, temos de tomar cuidado quando se afirma que categorias linguisticas omitidas no uso da fala por sujeitos acometidos por uma lesão são readquiridas. Em que sentido interpretamos essa reaquisição? Na próxima seção, discutiremos sobre a terminologia adotada para nomear a recuperação 
linguistica em pessoas que sofreram lesão cerebral e, para tanto, questionaremos a ideia da reaquisição de linguagem em adultos e defenderemos a favor de uma recuperação da capacidade comunicativa.

\section{Recuperação da capacidade comunicativa ou reaquisição de linguagem no tratamento da afasia em adultos?}

A afasia pode ser caracterizada por alterações no uso linguístico devido à lesão cerebral, o que afeta diretamente a capacidade comunicativa do sujeito. $\mathrm{O}$ tratamento/terapia visa, dentre outros pontos, recuperar essa capacidade comunicativa, de modo a inserir o afásico em suas atividades cotidianas. Nessa seção, como discutiremos a noção de aquisição de língua, faremos remissão a alguns postulados da teoria de Regência e Ligação (CHOMSKY, 1981), em especial, ao tratamento que a mesma apresenta para a questão da aquisição e, a partir desse conceito, comentaremos nossa opinião a esse respeito, argumentando em favor de uma recuperação da capacidade comunicativa em sujeitos afásicos em detrimento de uma (re)aquisição.

Gregolin-Guindaste (1996) defende que, no quadro do agramatismo, pode ocorrer reaquisição de linguagem, uma vez que foi observado no caso $P$ uma aquisição de categorias funcionais. Por outro lado, Grodzinsky (1990) diz que a reaprendizagem, se ocorrer, não parte da Faculdade de Linguagem, mas por intermédio de outros recursos cognitivos nãolingüísticos. No entanto, podemos chamar o processo de recuperação de um sujeito agramático de reaquisição do sistema lingüístico? Ou trata-se apenas de recuperação da capacidade comunicativa a partir da plasticidade neural?

A Teoria de Regência e Ligação (cf. CHOMSKY, 1981) trata a questão da aquisição da linguagem em termos de princípios universais comuns às diversas línguas existentes e de parâmetros que, por sua vez, são fixados pela criança ao longo de seu desenvolvimento linguístico. Nesse sentido, as variações observadas entre as línguas seriam resultado das distintas possibilidades de fixação desses parâmetros. Sabemos que, na aquisição da linguagem, a criança, que está adquirindo o sistema linguístico, marca os parâmetros, vindos do input, que lhe são oferecidos. Isso configura uma situação normal de aquisição.

Segundo Chomsky, os seres humanos adquirem a língua durante os anos iniciais de vida e, de certo modo, há um período crítico para o desenvolvimento da linguagem ${ }^{4}$. A criança nesse período tem acesso à Gramática Universal, aos princípios linguísticos. O input oferecerá à criança as particularidades de uma dada língua, que são processadas pelo seu aparato biológico. E até o final do processo de aquisição, a criança terá a gramática da(s) língua(s) que faz(iam) parte de seu ambiente.

Costuma-se falar em aquisição de linguagem para crianças no período de desenvolvimento natural. Mas quando o foco são pessoas adultas que sofreram lesão na região da linguagem, pode-se falar em processo de (re)aquisição de linguagem? A afasia causa perda de conhecimento linguístico ou alteração no uso da língua, na fala?

Isso vai depender do tipo de concepção de linguagem de que se parte e do que se entende por afasia. Partindo da teoria gerativa e da forma como está entende língua e a questão da aquisição, a idade em que o sujeito sofreu lesão será determinante, pois, se uma criança sofreu lesão no decorrer do chamado período crítico, é esperado que o processo de aquisição continue, já que a gramática da língua ainda nao foi adquirida e a criança nesse caso tem acesso à GU. O termo apropriado a ser usado nessa situação será aquisição de linguagem, pois o processo ainda está em curso ${ }^{5}$. Para Lent (2001, p. 144), "crianças portadoras de lesões corticais que atingem as regiões lingüísticas são suscetíveis de

\footnotetext{
4 Tem-se defendido um período crítico na aquisição de linguagem, mas não há consenso na literatura a respeito de qual seria esse período. A depender do que se entende por cérebro, linguagem, desenvolvimento linguístico-cognitivo, teremos diferentes idades para encerrarem o período crítico. Para informações, ver Lenneberg, (1967), Bishop e Mogford (2002), Lent (2001). Assumimos neste artigo que há um período (na infância) em que a gramática da criança se completa e daí não há mais acesso à GU.

${ }^{5}$ Newport (1990), tomando como base a maturação linguística, afirma que crianças que sofreram lesão cerebral recuperam a linguagem melhor do que os adultos, pois a maturação, segundo ela, na infância ainda está em processo.
} 
considerável recuperação funcional quando as lesões ocorrem durante o período crítico. Lesões semelhantes que atingem adolescentes ou adultos jovens provocam déficits de difícil recuperação. " O fato da existência do período crítico indica que a gramática ainda está em formação. Nos adultos, por outro lado, a gramática ja foi adquirida e não é perdida na afasia, já que esta diz respeito apenas às alterações na fala.

Sendo assim, não há evidências claras de (re)aquisição de língua no adulto afásico, até porque o que há na afasia é uma alteração no uso da fala, não há comprometimento do conhecimento linguístico. Para falar em aquisição ou (re)aquisição de língua, é necessário comprovar que o conhecimento que se tem da língua foi perdido. $A$ seguir, apresentaremos uma situação que demonstra que ser afásico não significa não saber mais a língua, comentada por um afásico:

SL conta seu primeiro impacto sobre o que é a afasia e a condição de ser afásico. No início do tratamento a fonoaudióloga lhe disse que seria preciso aprender tudo de novo. Só se for em alemão, respondeu ele. A situação por que passou SL faz pensar, por um lado, na complexidade do fenômeno da afasia - tal como a linguagem e, por outro lado, na banalidade como é tratado o sujeito afásico, supondo que perdeu, esqueceu tudo que sabe, que co-ocorre um declínio de inteligência e tudo isso em uma relação assimétrica em que um sabe tudo e o outro não sabe nada. (COUDRY, 2008, p. 08)

SL é um sujeito da linguagem e o fato de estar afásico não o tira dessa posição. Nesse caso, preferimos falar que há recuperação da capacidade comunicativa, já que na afasia há apenas uma alteração no uso da língua. Para argumentar em favor de uma (re)aquisição, é necessário dizer que houve perda, mas quais as evidências para demonstrar isso? Pela ausência de evidências para comprovar perda de língua, de conhecimento linguístico, preferimos falar nesses quadros de afasia em recuperação de sujeitos de sua capacidade comunicativa a partir de alterações no ambiente e da atuação da plasticidade cerebral, pois outros níveis no cérebro podem agir para o sujeito conseguir se comunicar. Um sujeito com agramatismo, por exemplo, pode recuperar sua capacidade comunicativa e esse quadro, o do agramatismo, não muda em natureza, apenas há uma alteração de grau, ou seja, o déficit fica menos acentuado. Então, retomando a questão (iii) apresentada no início do artigo, pode-se falar em termos teóricos em processo de (re)aquisição de linguagem em sujeitos adultos afásicos? Nossa resposta é não. Não achamos conveniente chamar de reaquisição de linguagem o processo de recuperação da capacidade comunicativa de um quadro patológico, pois implica trazer questões relacionadas à aquisição em desenvolvimento natural e implica dizer que há perda de conhecimento linguístico por parte do sujeito. É importante entender primeiro o que é a afasia, como é a linguagem na afasia, no ser afásico, como são as dificuldades de falar, ler, escrever. Nessa direção, apresento o seguinte texto:

Os dados mostram que a afasia submete o sujeito afásico a não dizer algo e a dizer/mostrar/fazer outra coisa em seu lugar; outras palavras ocupam o lugar da palavra pretendida, sendo muitas vezes difíceis de serem abandonadas; por isso são repetidas e retornam sempre na fala: restos de linguagem para Freud (1891/1973), um dizer sem inibição que ocupa 0 dito pretendido. Um deslocamente com substituição (Freud, 1901/1969). Da perspectiva discursiva, para além da lesão cerebral, um sujeito é afásico quando Ihe faltam recursos de produção e interpretação para exercer a linguagem, sem, no entanto, faltar-lhe a função cognitiva/psíquica de poder traduzir, por meio de processos alternativos de significação, o que quer dizer. Faz isso por meio de silêncios com expressividade, palavras que não são ditas, segmentos de palavras, não-palavras e palavras que involuntariamente se apresentam entremeadas pela presença do corpo, de gestos, percepções, associações, objetos, ações, possibilidade de (re)dizer o novo no velho que caracterizam a linguagem em estados de afasia. (COUDRY, 2008, p. 32).

$\mathrm{Na}$ próxima seção, apresentaremos as considerações finais desse trabalho.

\section{Considerações finais}

A afasia é uma caixinha de surpresas. Nossa convivência no CCA, fez-nos observar que (i) de nada 
adianta ficar dando nomes às várias faces que uma patologia como essa pode ter, mas sabemos também que as nomear pode nos ajudar a direcionar a situação discursiva e inserir contextos em que 0 sujeito possa se relacionar diretamente com a linguagem, fazendo uso de diferentes recursos para recuperar sua capacidade comunicativa; (ii) 0 processo de recuperação é gradual, lento, requer paciência e parceria (entre afásico e terapeuta; afásico e família; terapeuta e família do afásico); (iii) em cada sessão surge uma novidade: Cada dia eles redescobrem maneiras variadas para se comunicarem, às vezes, a escrita os ajuda a falar, em outros momentos, a fala desencadeia a escrita, os gestos, as expressões faciais, tudo faz parte de um todo que é cotidianamente recuperado através de práticas discursivas vivenciadas nas sessões; (iv) testes $^{6}$, atividades mecânicas não surtem efeito no processo de recuperação, porque não trazem sentido para a comunicação. Daí a necessidade de assumir a intervenção clínica tendo como base uma linguagem discursivamente orientada, em que há uma relação estreita entre sujeito e linguagem, de modo que aquele possa fazer uso das situações como exercício com e sobre a linguagem, que é o lócus por excelência da significação, dos sentidos, ou seja, a solução é pragmática (cf. COUDRY, 1996).

Vimos também que o ser humano é extremamente capaz de se adaptar às diferentes situações que the aparecem. O cérebro, nesse sentido, passa por modificações funcionais para se adaptar às situações que the são impostas. A neurociência tem cada vez mais verificado a atuação da plasticidade cerebral no indivíduo. E uma das grandes descobertas é a de que o ambiente de alguma maneira atua sobre o sistema nervoso, modificando-o, restaurando funções alteradas. Nesse sentido, reafirmamos a importância da ND na reabilitação de pessoas acometidas por lesão, provocando atividades linguísticas que estimulem a plasticidade neural, a articulação entre os níveis da

\footnotetext{
${ }^{6}$ Os testes servem apenas para confirmação de hipóteses, não nos permitem avaliá-los ou tratá-los.
}

língua e, enfim, estimulem a recuperação da capacidade comunicativa do sujeito.

Todas essas práticas com e sobre a linguagem, atividade significativa com a interlocução do paciente e do terapeuta e da família são fundamentais para a recuperação da capacidade comunicativa do sujeito.

\section{Referências}

BISHOP, D; MOGFORD, K. Desenvolvimento da linguagem em circunstâncias excepcionais. Rio de Janeiro: Editora Revinter, 2002.

CHOMSKY, N. Lectures on Government and Binding. Holland: Foris Dordrecht Publications, 1981.

COUDRY, M. I. H. Neurolinguistica Discursiva: Afasia como tradução. Estudos da Lingua(gem)v. 6, n. 2, p. 7-36, 2008.

Linguagem e Afasia: Uma abordagem discursiva da Neurolingüística In: Cadernos de Estudos Linguísticos, 42, Campinas, IEL, UNICAMP, p. 99129, 2002.

O que é o dado em Neurolingüística. In: CASTRO, M. F. P. (Org.) O método e o dado no estudo da linguagem. Campinas: Editora da UNICAMP, 1996.

Diário de Narciso: discurso e afasia. São Paulo: Martins Fontes, 1988.

FRANCHI, C. Linguagem - Atividade Constitutiva. Cadernos de Estudos Linguísticos. Campinas, n. 22, 1992, p. 9-39. Texto original: 1977.

FREIRE, F.; COUDRY, M. I. H.; GOMES, T. Sem falar, escrever e ler e ainda sujeito da linguagem. Estudos Linguísticos.XXXV, p. 1375-1384, 2006.

GOMES T. de M. Quatro estados de afasia e um sujeito da linguagem: um estudo neurolingüístico. Dissertação de Mestrado. Campinas: IEL/UNICAMP, 2008.

GREGOLIN-GUINDASTE, R. O agramatismo: um estudo de caso em Português. Campinas: Instituto de Estudos da linguagem, Unicamp (Tese de Doutorado), 1996.

GRODZINSKY, Y. Theoretical perspectives on language deficits. Cambridge: MIT Press, 1990.

LENNEBERG, E. H. Biological Foundations of Language. New York: Wiley, 1967.

LENT, R. Cem Bilhões de Neurônios - Conceitos Fundamentais da Neurociência. São Paulo: Atheneu, 2001. 
LURIA, A. R. Fundamentos em Neuropsicologia. São Paulo: EDUSP, 1981.

NESPOULOUC, Jean-Luc; DORDAIN, Monique. Agramatismo: Alteração Sintática ou Morfemática? Um Estudo de Caso. In: MANSUR, Letícia; RODRIGUES, Norberto. Temas em Neurolingüística. Vol. 2. São Paulo: Tec Art, 1993.

NEWPORT, E. Maturacional constraints on language learning. Cognitive Science. 14, p. 11-28, 1990.
NOVAES, Celso. Teorias da Linguagem: A Gramática Gerativa e as Patologias da Linguagem. II Fórum de Linguagem, Natureza e Cultura. UFRJ: Rio de Janeiro, 2006.

TUMIATE, C. Considerações sobre o agramatismo: Seus traçados e tropeços. Dissertação de Mestrado. 81f. PUC: São Paulo, 2007.

\section{COMO CITAR ESSE ARTIGO}

DE OLIVEIRA, Vivian Meira. A NEUROLINGUÍSTICA DISCURSIVA E A RECUPERAÇÃO DA CAPACIDADE COMUNICATIVA DE SUJEITOS AFÁSICOS. Signo, Santa Cruz do Sul, v. 41, n. 71, set. 2016. ISSN $1982-2014$. Disponível em: <https://online.unisc.br/seer/index.php/signo/article/view/7258>. Acesso em: . doi: http://dx.doi.org/10.17058/signo.v41i71.7258. 